LAWRENCE LIVERMORE N A T IO N A L LABORATORY
Investigating the Affinities and Persistence of VX Nerve Agent in Environmental Matrices

A. H. Love, A. L. Vance, J. G. Reynolds, M. L. Davisson

April 2, 2004

Chemosphere 
This document was prepared as an account of work sponsored by an agency of the United States Government. Neither the United States Government nor the University of California nor any of their employees, makes any warranty, express or implied, or assumes any legal liability or responsibility for the accuracy, completeness, or usefulness of any information, apparatus, product, or process disclosed, or represents that its use would not infringe privately owned rights. Reference herein to any specific commercial product, process, or service by trade name, trademark, manufacturer, or otherwise, does not necessarily constitute or imply its endorsement, recommendation, or favoring by the United States Government or the University of California. The views and opinions of authors expressed herein do not necessarily state or reflect those of the United States Government or the University of California, and shall not be used for advertising or product endorsement purposes. 


\title{
Investigating the Affinities and Persistence of VX Nerve Agent in Environmental Matrices
}

\author{
Adam H. Love, Andrew L. Vance, John G. Reynolds, M. Lee Davisson \\ Lawrence Livermore National Laboratory \\ PO Box 808 \\ Livermore, CA 94551
}

Corresponding Author: Adam H. Love, Lawrence Livermore National Laboratory, PO Box 808, L-396, Livermore, CA 94551. Phone: 925-422-4999. Fax: 925-424-3255. email: love5@1lnl.gov

\begin{abstract}
Laboratory experiments were conducted to determine environmental variables that affect the affinities and persistence of the nerve agent O-ethyl S-(2diisopropylaminoethyl) methylphosphonothiolate (VX) at dilute concentrations in environmental matrices. Quantitative analyses of VX and its degradation products were performed using LC-MS. Batch hydrolysis experiments demonstrated an increasing hydrolysis rate as $\mathrm{pH}$ increased, as shown in previous studies, but also indicated that dissolved aqueous constituents can cause significant differences in the absolute hydrolysis rate. Adsorption isotherms from batch aqueous experiments revealed that VX has a high affinity for hydrophobic organics, a moderate affinity for montmorillonite clay, and a very low affinity for an iron-oxyhydroxide soil mineral, goethite. The adsorption on goethite was increased with the presence of dissolved organic matter in solution. VX degraded rapidly when dried onto goethite, when an inner-sphere complex was forced. No enhanced degradation occurred with goethite in small amounts water. These results suggest that aqueous conditions have important controls on VX adsorption and degradation in the environment and a more mechanistic understanding of these
\end{abstract}


controls is needed in order to enable accurate predictions of its long-term fate and persistence.

Keywords: organophosphorus, degradation, adsorption, catalysis, hydrolysis, chemical weapons

\section{INTRODUCTION}

Given their extreme toxicity and strict controls, organophosphorus nerve agents are a unique chemical class whose environmental persistence has been poorly characterized, even though there would likely be concern about environmental contamination if the chemical were released. O-ethyl S-(2-diisopropylaminoethyl) methylphosphonothiolate (VX) has a low volatility and is a very toxic organophosphorus nerve agent. Its environmental behavior is complicated because its structure has functional groups that can be potentially basic or acidic while exhibiting hydrophobic properties. In addition, VX lacks a strong electron-withdrawing group common to most organophosphorus pesticides that would increase its potential for degradation. Chemical surrogates of organophosphorus nerve agents having low toxicity (Table 1), do not share the same structural properties. This suggests VX may behave significantly differently in environmental matrices than compounds used as surrogates depending on prevailing $\mathrm{pH}$, temperature, and affinity toward adsorptive or reactive surfaces.

The majority of information known about the behavior of VX in the environment is derived primarily from empirical military field experiments conducted at high concentrations approximately 50 years ago with very little documented controls (Kingery and Allen, 1995), or from laboratory studies conducted on one soil type under a single simulated condition (Verweij and Boter, 1976; Kaaijk and Frijlink, 1977). Both of these approaches reported relatively rapid disappearance of VX. In contrast, recent studies on 
concrete and other soil types reported significantly slower VX degradation rates than previously documented (Wagner et al., 2001a; Groenewold et al., 1999), suggesting natural variations in environmental conditions or matrices can lead to significant differences in its environmental persistence. Nonetheless, a more thorough understanding of VX fate in the environment has not been established.

This paper reports the results from the initial effort to identify specific factors that affect the affinity and persistence of VX in dilute concentration and thus differs from previous work conducted at much higher concentrations. We focused primarily on typical environmental conditions with common, but simplified matrices. It is also the first paper that reports quantitative analyses of VX and its degradation products using LC-MS. The hydrolysis and adsorption experiments performed were relatively simple, but provide the first steps in building a more comprehensive understanding of the behavior of VX in the environment.

\section{EXPERIMENTAL SECTION}

\section{Caution}

VX is a highly toxic compound that can harm exposed individuals at extremely small doses (e.g. $\mathrm{LD}_{50} \sim 1 \mathrm{mg} / \mathrm{kg}$ ) and should be handled only in appropriate facilities. In addition, international treaties tightly regulate possession of $\mathrm{VX}$ and handling is only permitted in laboratories approved for chemical warfare agents under strict security. The Forensic Science Center at Lawrence Livermore National Laboratory (LLNL) has the authority and capability to synthesize and handle small, dilute quantities of VX through its accreditation as a United States testing facility for the Organization for the Prohibition of Chemical Weapons, which performs monitoring for verification of international 
treaties that ban chemical weapons. Thus, this resource enables trace-level environmental research of CW compounds to occur at LLNL.

\section{Reagents}

Dilute solutions of VX (800 ppm of VX in $10 \mathrm{~mL}$ of methylene chloride) were synthesized at LLNL and the purified product was quantified using GC-AED. The purity of VX was $>99 \%$. The chemicals were purchased as follows: methyl phosphonic acid (MPA), O-ethyl methylphosphonic acid (EMPA), HPLC grade methanol, water, formic acid, ammonium formate, sodium citrate, 3-(N-Morpholino)propanesulfonic acid (MOPS) - Sigma Chemical Co., St. Louis, MO; powdered activated charcoal - MCB Manufacturing Chemists, Inc., Cincinnati, OH; montmorillonite - Aldrich Chemical Co., Milwaukee, WI; sand, ferric chloride - J.T. Baker, Phillipsburg, NJ; Suwanne River fulvic acid - International Humic Substances Society, St. Paul, MN; anhydrous sodium carbonate - Mallinckrodt Chemical Works, St. Louis, MO. Goethite was synthesized from ferric chloride according to Schwertmann and Cornell (1991).

\section{LC-MS Conditions}

A ThermoFinnigan Surveyor with quaternary pump and autosampler was fitted with a $150 \times 2.0 \mathrm{~mm}$ ID Supelco C18 bonded silica column with $5 \mu \mathrm{m}$ particle size, matching guard column, and stainless steel frits prefilter. Conditions were modeled after those of Read and Black (1999) and Black and Read (1998). However isocratic conditions provided superior quantitative reproducibility than the gradient elutions. Separate chromatographic runs were used for VX and the phosphonic acid degradation 
products. The 5-min isocratic elution for VX was $60 \%$ water/ $40 \%$ methanol with $1 \%$ formic acid at $0.2 \mathrm{ml} / \mathrm{min}$; for MPA and EMPA, 95\% water/ $5 \%$ methanol with $0.02 \%$ ammonium formate. Aqueous injections of $10 \mu \mathrm{l}$ were made from $200 \mu \mathrm{L}$ silanized inserts within $2 \mathrm{ml} \mathrm{HPLC}$ vials using the autosampler.

The column effluent was directed into the ThermoFinnigan LCQ Advantage MS via an electrospray interface resulting in lower quantification limits than atmospheric

pressure chemical ionization source. VX was quantified in positive mode $[\mathrm{M}+\mathrm{H}]^{+}$at $\mathrm{m} / \mathrm{z}$ 268. MPA and EMPA were quantified in negative mode $[\mathrm{M}-\mathrm{H}]^{-}$at $\mathrm{m} / \mathrm{z} 95$ and 123 , respectively. VX had a linear response in the range of 0.005 to $5 \mathrm{ppm}$, with a detection limit of $0.005 \mathrm{ppm}$. MPA and EMPA had a linear response from 1 to $100 \mathrm{ppm}$, with a detection limit of $1 \mathrm{ppm}$. Analytical variability using this methodology is typically 5$10 \%$.

\section{Hydrolysis Experiments}

VX hydrolysis experiments (Table 2) were run for 28 days in disposable Teflon ports of an Argonaut Technologies Quest 210 parallel synthesizer. The parallel synthesizer allowed the solution to be mixed continuously with a Teflon stir bar while remaining sealed. Thirteen ports were filled with $10 \mathrm{~mL}$ of solution with various buffer conditions. One port had deionized water equilibrated with atmospheric $\mathrm{CO}_{2}$. Three ports had deionized water buffered with $1 \mathrm{mM}$ citrate at $\mathrm{pH}$ 5. Three ports had deionized water buffered with $1 \mathrm{mM}$ MOPS at $\mathrm{pH}$ 7. Three ports had deionized water buffered with $1 \mathrm{mM}$ carbonate, initially at $\mathrm{pH} 11$. Three ports had deionized water buffered with $10 \mathrm{mM}$ carbonate at $\mathrm{pH} 11$. For each set of the buffer conditions, one of the ports had $100 \mathrm{mg} / \mathrm{L}$ 
of dissolved organic matter (DOM) from Suwanne River fulvic acid and another had $1000 \mathrm{mg} / \mathrm{L}$ goethite. After the solutions were allowed to equilibrate overnight, $12.5 \mu \mathrm{L}$ of the VX in methylene chloride stock solution was added to each solution, for a final VX concentration of $1 \mathrm{ppm}$. Each solution was analyzed periodically by sampling $\sim 500 \mu \mathrm{L}$ through a valve at the bottom of each port and filtering using a syringe filter.

Table 2. Table of VX Hydrolysis Experiments

\begin{tabular}{|l|l|l|l|l|l|}
\hline & DI Water & $\begin{array}{l}1 \mathrm{mM} \\
\text { Citrate }\end{array}$ & $\begin{array}{l}1 \mathrm{mM} \\
\text { MOPS }\end{array}$ & $\begin{array}{l}1 \mathrm{mM} \\
\text { Carbonate }\end{array}$ & $\begin{array}{l}10 \mathrm{mM} \\
\text { Carbonate }\end{array}$ \\
\hline Water only & $\mathrm{X}$ & $\mathrm{X}$ & $\mathrm{X}$ & $\mathrm{X}$ & $\mathrm{X}$ \\
\hline Goethite & & $\mathrm{X}$ & $\mathrm{X}$ & $\mathrm{X}$ & $\mathrm{X}$ \\
\hline DOM & & $\mathrm{X}$ & $\mathrm{X}$ & $\mathrm{X}$ & $\mathrm{X}$ \\
\hline
\end{tabular}

\section{Adsorption Experiments}

VX adsorption experiments were performed in $25 \mathrm{~mL}$ glass scintillation vials.

Each vial was filled with $10 \mathrm{~mL}$ of deionized water and $12.5 \mu \mathrm{L}$ of the VX in methylene chloride stock solution was added to each solution, for a final VX concentration of 1 ppm. Powdered activated charcoal, montmorillonite, and goethite were used to construct adsorption isotherms by adding a measured amount of solid into each vial, shaking vigorously for 1 minute and allowing the solution to equilibrate for 5 to $10 \mathrm{~min}$, which had been previously demonstrated to be adequate (data not shown). For adsorption isotherms of montmorillonite and goethite individually mixed with DOM, $100 \mathrm{mg} / \mathrm{L}$ solutions of DOM were allowed to equilibrate overnight with the solid substrate. The next day these vials were spiked with VX from $1 \mathrm{ppm}$ to $0.1 \mathrm{ppm}$, shaken, and allowed to equilibrate. After equilibration, the vial was shaken vigorously again and $500 \mu \mathrm{L}$ was 
sampled using a syringe, filtered at $0.45 \mathrm{um}$, and analyzed using LC-MS within a few hours of sampling.

\section{Enhanced Degradation on Goethite Experiments}

The experiment investigating the degradation of VX on goethite were performed in $25 \mathrm{~mL}$ silanized scintillation vials. Each of three vials had $50 \mathrm{mg}$ of goethite added. Two vials had $100 \mu \mathrm{L}$ of deionized water added, enough to wet the mineral surface but without any free water. Controls 1) with no solid and 2) with $50 \mathrm{mg}$ of dry sand were used for comparison. $1 \mathrm{~mL}$ of $50 \mathrm{ppm} \mathrm{VX}$ in methylene chloride was added to each vial, which was shaken vigorously and the cap removed. The methylene chloride was allowed to evaporate overnight in a fume hood. The next day $2.5 \mathrm{~mL}$ of water was used to elute the VX from the goethite surfaces of the dry goethite and one wet goethite. The last vial of wet goethite with VX was allowed to completely dry. A sample was taken with a syringe, filtered at $0.45 \mathrm{um}$, and analyzed using LC-MS.

\section{RESULTS AND DISCUSSION}

\section{VX Hydrolysis}

The VX hydrolysis results are shown in Figure 1a-1d as ratios of the measured VX concentration relative to its initial value. The $1 \mathrm{mM}$ citrate buffered solutions at $\mathrm{pH} 5$ (Fig. 1a) resulted in the slowest hydrolysis, yielding a uniform rate for the different 
matrices. Note, however, that deionized water, which had a $\mathrm{pH}$ of $\sim 5$, hydrolyzed VX significantly faster $\left(\sim 0.2\right.$ day $\left.^{-1}\right)$ than the buffered solutions $\left(0.01-0.03\right.$ day $\left.^{-1}\right)$. At $\mathrm{pH} 7$, buffered with $1 \mathrm{mM}$ MOPS, the deionized water and the water with goethite had similar hydrolysis rates of $\sim 0.2$ day $^{-1}$, whereas the water with dissolved organic matter (DOM) had a significantly slower hydrolysis rate, 0.09 day $^{-1}$ (Figure 1b). The waters buffered using $10 \mathrm{mM}$ carbonate at $\mathrm{pH} 11$ all had similar hydrolysis rates of $\sim 0.3-0.5$ day $^{-1}$ (Figure 1c). Water buffered using only $1 \mathrm{mM}$ carbonate was initially at $\mathrm{pH} 11$, but over the course of the hydrolysis experiment the $\mathrm{pH}$ dropped from 11 to 9 and then to 7 (Figure 1d). Nonetheless, the hydrolysis of VX remained constant, with the rate of the water and water with goethite having a hydrolysis rate of 0.21 days $^{-1}$ and the water with fulvic acid had a hydrolysis rate that was somewhat slower at 0.18 day $^{-1}$.

Epstein et al. (1974) measured the kinetics and described different mechanisms involved in the hydrolysis of $\mathrm{VX}$ from pure aqueous solutions over a $\mathrm{pH}$ range from 1 to 13. Although these experiment were done only on pure waters, where $\mathrm{HCl}$ and $\mathrm{NaOH}$ were used to control $\mathrm{pH}$, the equation from this paper that relates the observed hydrolysis rate $\left(\mathrm{k}_{\mathrm{obs}}\right)$ to $\mathrm{pH}$ (Equation 1) is often extended to applications in environmental systems (Kingery, 1995) dominated by natural buffers and other dissolved species.

$$
k_{o b s}=k_{H_{2} O} \frac{\left[H^{+}\right]}{K_{a}+\left[H^{+}\right]}+k \frac{K_{a}}{K_{a}+\left[H^{+}\right]}+k_{O H}\left[O H^{-}\right] \frac{K_{a}}{K_{a}+\left[H^{+}\right]}
$$

where: $\mathrm{k}_{\mathrm{H} 2 \mathrm{O}}=2.9 \times 10^{-4} \mathrm{hr}^{-1}, \mathrm{k}=1.5 \times 10^{-2} \mathrm{hr}^{-1}, \mathrm{k}_{\mathrm{OH}}=30 \mathrm{M}^{-1} \mathrm{hr}^{-1}, \mathrm{~K}_{\mathrm{a}}=2.5 \times 10^{-9}$ (From Epstein et al. 1974) 
The presence of other dissolved species may result in additional aqueous interactions that affect the observed VX hydrolysis rate. For example, competitive exclusion of other electron donating or withdrawing ions may slow down or accelerate VX hydrolysis, or VX affinity toward functional groups on dissolved/suspended species may cause similar changes. Thus, our hydrolysis experiments were designed as simple tests to quantitatively measure the hydrolysis rate under various aqueous conditions.

The hydrolysis rate from Epstein et al. (1974) and the hydrolysis data from this study are compared in Figure 2. Although the overall trend is similar, with slower hydrolysis at low $\mathrm{pH}$ conditions and greater hydrolysis at high $\mathrm{pH}$ conditions, it seems apparent that the type and quantity of dissolved species does significantly affect the observed hydrolysis rate. The presence of the $1 \mathrm{mM}$ buffers seem to increase the hydrolysis of VX compared to the rate in the hydrolysis equation from Epstein et al. (1974), whereas the $10 \mathrm{mM}$ carbonate buffer at $\mathrm{pH} 11$ was slower than the equation would have predicted. If it is assumed that deionized water that has equilibrated with the atmosphere is affected by carbonate buffering $(\sim 0.01 \mathrm{mM})$, it appears there is only a small decline in the hydrolysis rate as $\mathrm{pH}$ decreases from $\mathrm{pH} 11$ to 5, where carbonate/bicarbonate is the dominant buffer. In addition to the overall role of buffers, it is important to note that at $\mathrm{pH} 7$ the dissolved organic matter additionally seemed to slow the hydrolysis rate of VX.

VX is thought to typically degrade from electron acceptance on the phosphorus due to interactions with anionic nucleophiles (Yang, 1999). Compared to the rates reported by Epstein et al. (1974), discrepancies in hydrolysis rates observed in the 
buffered solutions reported here reflect aqueous conditions that contain nucleophiles other than hydroxide at higher concentrations that may dominate the overall hydrolysis. The batch reactors from Epstein et al. (1974) used an autotitrator with sodium hydroxide to control $\mathrm{pH}$, whereas the batch reactor reported here controlled $\mathrm{pH}$ with various buffers. Examining relative nucleophilicities using Swain-Scott $n$ values based on reactions with methyl bromide (Schwarzenbach, et al. 1993) for some of these dissolved constituents reveals that hydroxide, $n=4.2$, has the greatest nucleophilicity of the dissolved species in these aqueous system, whereas the nucleophilicity of bicarbonate, $n=3.8$, is less than hydroxide, and acetate, $n=2.7$, is the nucleophile listed that is closest in structure to citrate. However, in our buffered solutions the equilibrium concentration of hydroxide was over two orders of magnitude less than the bicarbonate concentration over all $\mathrm{pH}$ ranges (Snoeyink and Jenkins, 1980). Therefore, although other dissolved species are weaker nucleophiles than hydroxide, higher concentrations of these species may result in their dominance in the hydrolysis of VX. The observed hydrolysis rates reported by Epstein et al. (1974) are likely only applicable for aqueous systems where hydroxide is the dominant nucleophile, which have limited environmental applicability. In order to predict the persistence of VX in more likely environmental aqueous matrices, a more complete understanding is required of both the potential nucleophiles that can affect hydrolysis as well as other dissolved components that may enhance or interfere with degradation. 


\section{VX Adsorption Affinity}

The low volatility of VX, its different protonation states, and the hydrophobicity of the diisopropyl group suggest that VX is prone to partition onto solid surfaces. VX adsorption isotherms on materials that represent surfaces in the natural environment have never previously been reported. The VX adsorption isotherms for powdered activated charcoal (a surrogate for particulate organic matter), montmorillonite (a common clay mineral), and goethite (a common iron soil mineral) are shown in Figure 3. The activated charcoal clearly has the greatest affinity for VX, which should not be surprising since activated charcoal is used widely as an adsorbent for dissolved organics. This result is additionally supported by the fact that VX has an octanol-water partition coefficent of 120 (Munro et al., 1999), and thus has a strong affinity for hydrophobic interactions. Montmorillonite has a moderate affinity for VX and the goethite has little affinity. The low affinity of VX for goethite additionally explains why the hydrolysis experiments that contained $1000 \mathrm{mg} / \mathrm{L}$ goethite did not have observable differences in hydrolysis rate when compare to the solutions without goethite (Figures 1a-c). The addition of fulvic acid to the solution containing montmorillonite and goethite enhanced the adsorption of VX onto goethite, but showed little effect with montmorillonite. This may be the result of fulvic acids neutralizing charge on the goethite surface, thus permitting the hydrophobic adsorption of VX. The fulvic acid did not increase or decrease VX adsorption onto montmorillonite, suggesting that VX and the fulvic acids exploit different surface sorption sites on the clay. 


\section{Surface Reactions of VX with Goethite}

Studies of the persistence of VX on solid surfaces often apply it onto a dry mineral surface as a neat liquid or in a solvent and report rapid degradation of VX (Wagner et al, 2001b; Wagner et al., 1999; Groenewold et al. 1999; Verweij and Boter, 1976). Although this form of VX application is often described as adsorption, VX may not necessarily have an affinity for the mineral surface (i.e. goethite) and thus any interaction could be the result of a forced juxtaposition. In the environment, most soil mineral surfaces are coated with water and thus most interactions of VX with mineral surfaces are likely the consequence of an adsorption process where water plays a crucial role. Since the VX adsorption isotherm did not exhibit an affinity for goethite, the opportunity to examine the difference in persistence between VX application on wet and dry goethite was explored.

The results of applying VX in methylene chloride to wet and dry goethite is shown in Figure 4. The control (empty vial) and the dry sand show 100\% recovery of the VX applied in the solvent and extracted the next day with water, thus ruling out vapor loss using this approach. The VX applied to the dry goethite had 0\% recovered, and $>90 \%$ of the degradation product EMPA was extracted. VX applied to the wet goethite had $\sim 60 \%$ recovered, with $\sim 30 \%$ of the degradation product EMPA extracted. Lastly, VX applied to wet goethite, where the methylene chloride and the water were allowed to dry completely also had $0 \%$ VX recovered, and $~ 100 \%$ of the EMPA was extracted.

This difference in persistence is the result of inner-sphere complex formation on dry goethite (Wijnja and Schulthess, 2000), allowing the mineral surface to catalytically degrade VX, whereas the wet goethite had no affinity for VX in the aqueous phase. 
Dannenburg and Pehkonen (1998) demonstrated that goethite was able to catalytically hydrolyze organophosphorus pesticides when adsorbed to specific binding sites as innersphere complexes. The formation of an inner-sphere complex reduced the electron density at the central phosphorus, which enhances nucleophilic attack. Thus, the likely cause of only $\sim 60 \% \mathrm{VX}$ recovery from wet goethite was due to some drying of the mineral surface overnight, permitting catalytic degradation, while most of the remaining mineral surface remained hydrated and allowed VX to avoid formation of surface complexes. The dramatic differences in persistence when applying VX to wet and dry minerals reinforces the need to conduct experiments under realistic environmental conditions if results are used to predict the fate of VX in the environment.

\section{CONCLUSIONS}

Understanding the ultimate fate of VX in environmental systems involves a complex interaction of factors related to the solid, liquid, and gaseous phases. These results indicate that the hydrolysis equation by Epstein et al. (1974) may be inadequate to accurately predict the aqueous hydrolysis rate in environmental systems where natural dissolved species are present, and highlights the need to examine in more detail the role of naturally occurring nucleophiles in VX hydrolysis. The adsorption isotherms demonstrate the natural affinities VX has to a few naturally occurring minerals, but further study of additional substrates and various aqueous conditions is needed to understand how the affinities change in different soil and aqueous compositions. The persistence of VX on goethite is strongly affected by the presence or absence of water, which may also be true for other minerals that catalyze VX degradation. Still, there is 
much information that needs to be acquired if we intend to have a dependable predictive capability of the environmental fate of VX. The approach taken here, performing quantitative experiments that examining individual factors in simple systems, should lead to a level of mechanistic understanding that allows more complex environmental systems to be developed without convoluting the important factors that govern the fate of VX.

\section{ACKNOWLEDGMENTS}

This work was performed under the auspices of the U.S. Department of Energy by University of California, Lawrence Livermore National Laboratory under Contract W7405-Eng-48 and supported by the Laboratory Directed Research and Development (LDRD) Program at Lawrence Livermore National Laboratory (03-ERĐ 022). 


\section{REFERENCES}

Black, R.M.; Read, R.W. Analysis of degradation products of organophosphorus chemical warfare agents and related compounds by liquid chromatography-mass spectrometry using electrospray and atmospheric pressure chemical ionization. Journal of Chromatography A. 1998. 794:233-244.

Dannenberg, A.; Pehkonen, S.O. Investigation of the heterogeneously catalyzed hydrolysis of organophosphorus pesticides. Journal of Agricultural and Food Chemistry. 1998. 46:325-334.

Epstein, J.; Callahan, J.J.; Bauer, V.E. The kinetics and mechanisms of hydrolysis of phosphonothiolates in dilute aqueous solutions. Phosphorus. 1974. 4:157-163.

Groenewold, G.S.; Appelhans, A.D.; Gresham, G.L.; Olson, J.E.; Jeffery, M.; Wright, J.B. Analysis of VX on soil particles using ion trap secondary mass spectrometry. Analytical Chemistry. 1999. Vol. 71 (13):2318-2323.

Groenewold, G.S.; Williams, J.M.; Appelhans, A.D.; Gresham, G.L.; Olson, J.E.; Jeffery, M.T.; Rowland, B. Hydrolysis of VX on concrete: Rate of degradation by direct surface interrogation using an ion trap secondary ion mass spectrometer. Environmental Science and Technology. 2002. 36(22):4790-4794.

Kaaijk, J.; Frijlink, C. Degradation of S-2-di-isopropylaminoethyl O-ethyl methylphosphonothioate in soil: Sulfur-containing products. Pesticide Science. 1977. 8:510-514.

Kingery, A.F.; Allen, H.E. The environmental fate of organophosphorus nerve agents: A review. Toxicological and Environmental Chemistry. 1995. 47:155-184.

Munro. N.B.; Talmage, S.S.; Griffin, G.D.; Waters, L.C.; Watson, A.P.; King, J.F.; Hauschild, V. The sources, fate, and toxicity of chemical warfare agent degradation products. Environmental Health Perspectives. 1999. 107(12): 933-974.

Read, R.W.; Black, R.M. Rapid screening procedures for the hydrolysis products of chemical warfare agents using positive and negative ion liquid chromatography -mass spectrometry with atmospheric pressure chemical ionization. Journal of Chromatography A. 1999. 862:169-177.

Schwarzenbach, R.P.; Gschwend, P.M.; Imboden, D.M. Environmental Organic Chemistry. John Wiley \& Sons, Inc. New York. 1993. p. 359.

Schwertmann, W.; Cornell, R.M. Iron Oxides in the Laboratory: Preparation and Characterization. VCH, Weinheim. 1991. pp 64-71. 
Snoeyink, V.L.; Jenkins, D. Water Chemistry. John Wiley \& Sons, Inc. New York. 1980. p. 162-164.

Verweij, A.; Boter, H.L. Degradation of S-2-di-isopropylaminoethyl O-ethyl methylphosphonothioate in soil: Phosphorus-containing products. Pesticide Science. 1976. 7:355-362.

Wagner, G.W.; O'Connor, R.J., Procell, L.R. Preliminary study on the fate of VX in concrete. Langmuir. 2001a. 17:4336-4341.

Wagner G.W.; Procell, L.R.; O’Connor, R.J.; Munavalli, S.; Carnes, C.L.; Kapoor, P.N.; Klabunde, K.J. Reactions of VX, GB, GD, and HD with nanosize $\mathrm{Al}_{2} \mathrm{O}_{3}$ : Formation of aluminophosphonates. Journal of the American Chemical Society. 2001b. 123:16361644.

Wagner, G.W.; Bartram, P.W.; Lucas, E.; Decker, S.; Klabunde, K.J. Reactions of VX, GD, and HD with nanosize MgO. Journal of Physical Chemistry B. 1999. 103:32253228.

Wijnja, H.; Schulthess, C.P. Vibrational spectroscopy study of selenate and sulface adsorption mechanism on $\mathrm{Fe}$ and $\mathrm{Al}$ (Hydr)oxide surfaces. Journal of Colloid and Interface Sciences. 2000. 229:286-297.

Yang, Y. Chemical detoxification of nerve agent VX. Accounts of Chemical Research. 1999. 32(2):109-115. 


\section{FIGURE CAPTIONS}

Table 1. Log Kow values and structures for VX and selected low toxicity surrogates.

Figure 1a-1d. Hydrolysis of VX in water a) $\mathrm{pH} 5$ deionized water and $\mathrm{pH} 5$ water buffered with $1 \mathrm{mM}$ citrate b) $\mathrm{pH} 7$ water buffered with $1 \mathrm{mM}$ MOPS buffer c) $\mathrm{pH} 11$ water buffered with $10 \mathrm{mM}$ sodium carbonate d) water buffered with $1 \mathrm{mM}$ carbonate initially at $\mathrm{pH} 11$ that subsequently decreased to $\mathrm{pH} 7$.

Figure 2. Comparison of experimental results from Figure 1a-1d with the hydrolysis equation (1) from Epstein et al.(1974).

Figure 3. VX adsorption onto different substrates

Figure 4. Degradation results from applying VX onto wet and dry goethite. 
Table 1.

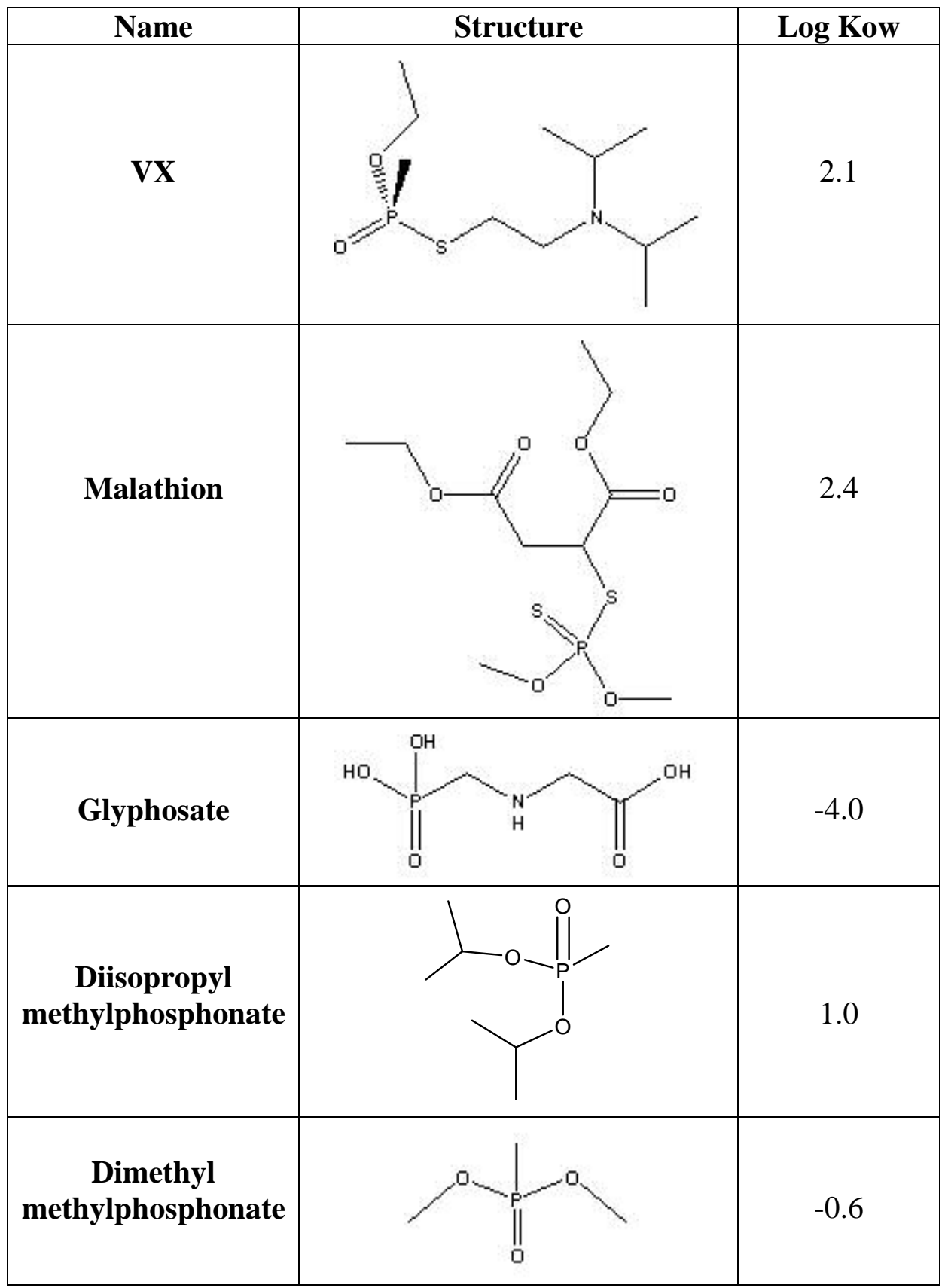


Figure 1a-1d

1a

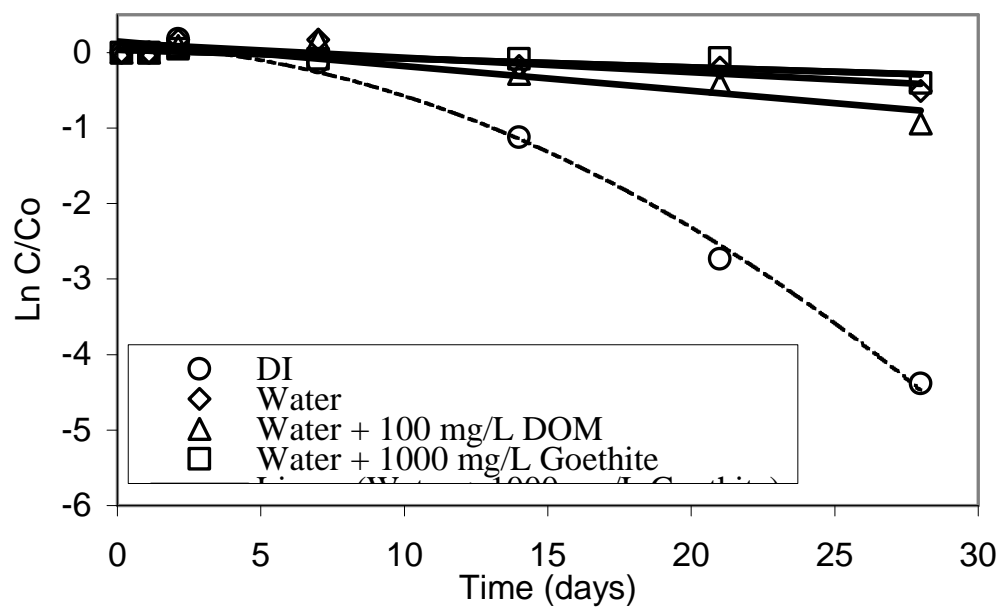

$1 b$

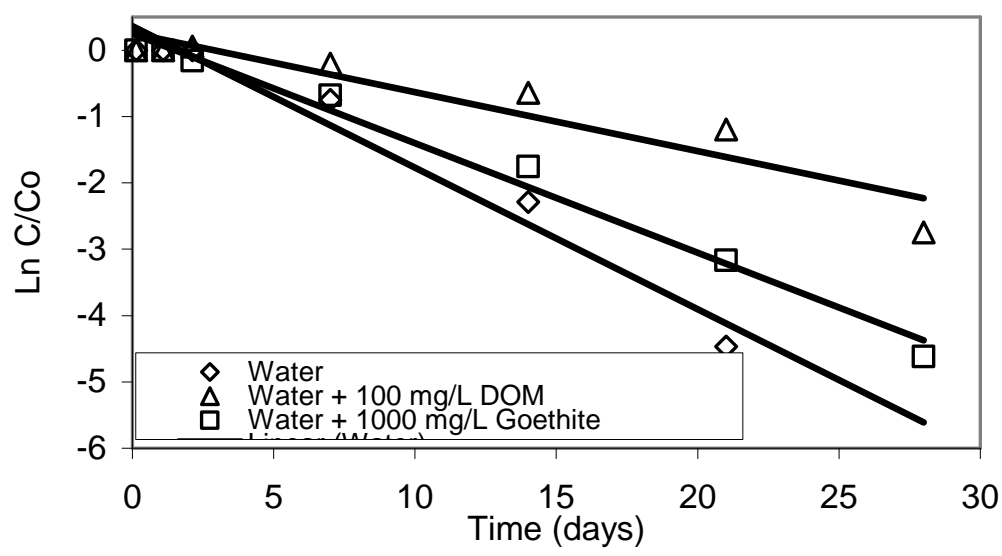

$1 c$

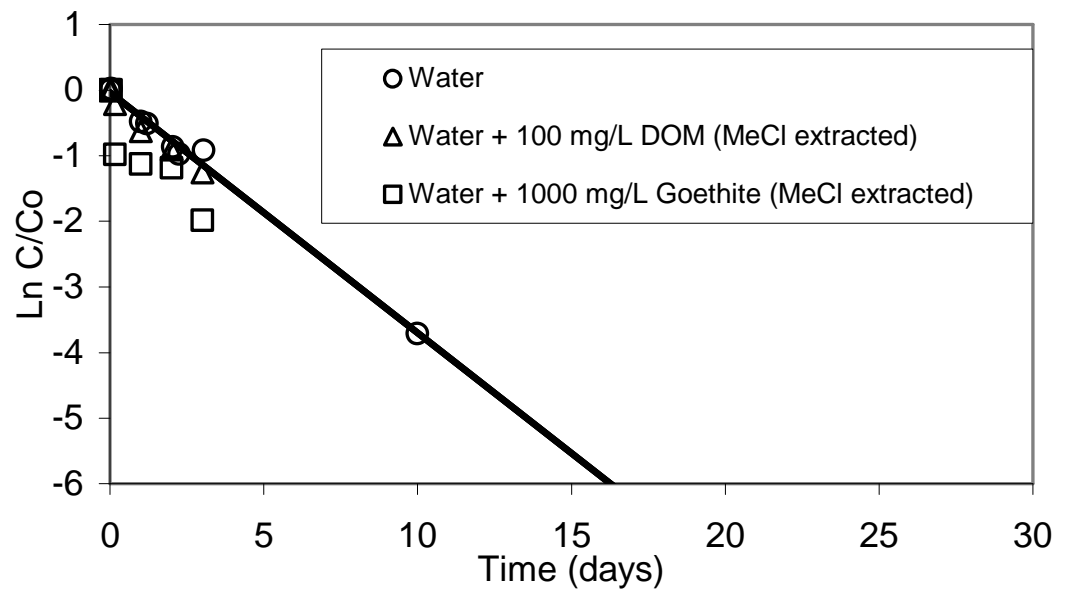




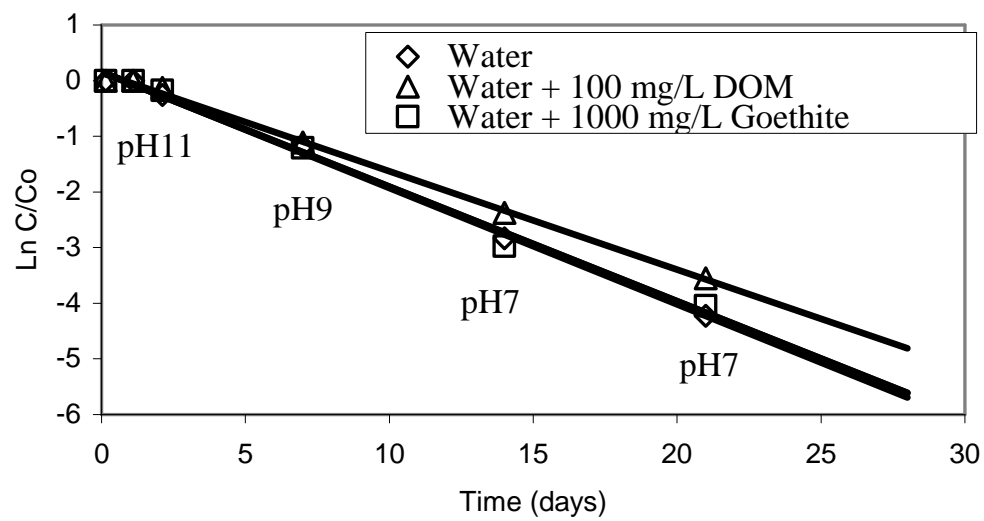


Figure 2

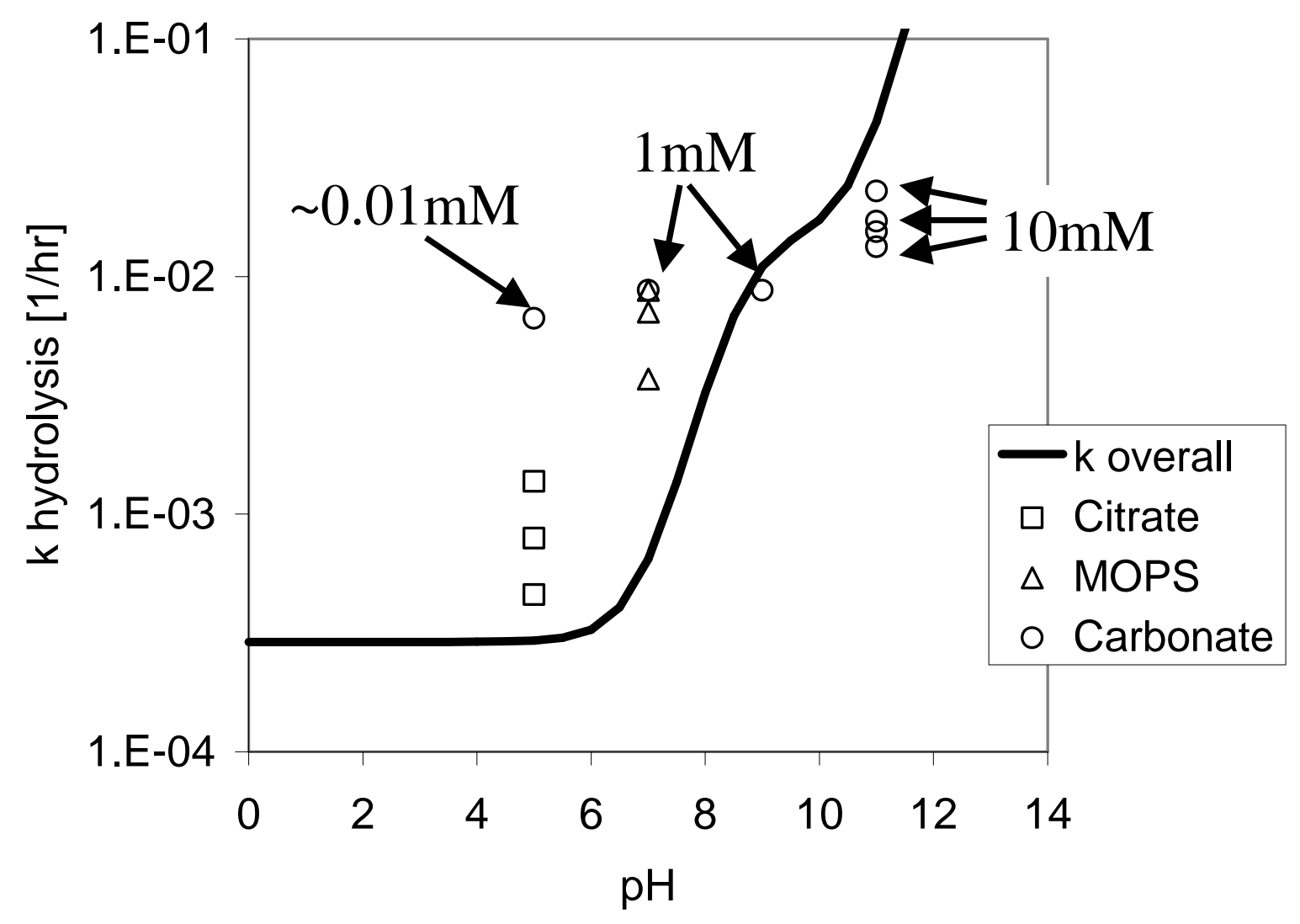


Figure 3

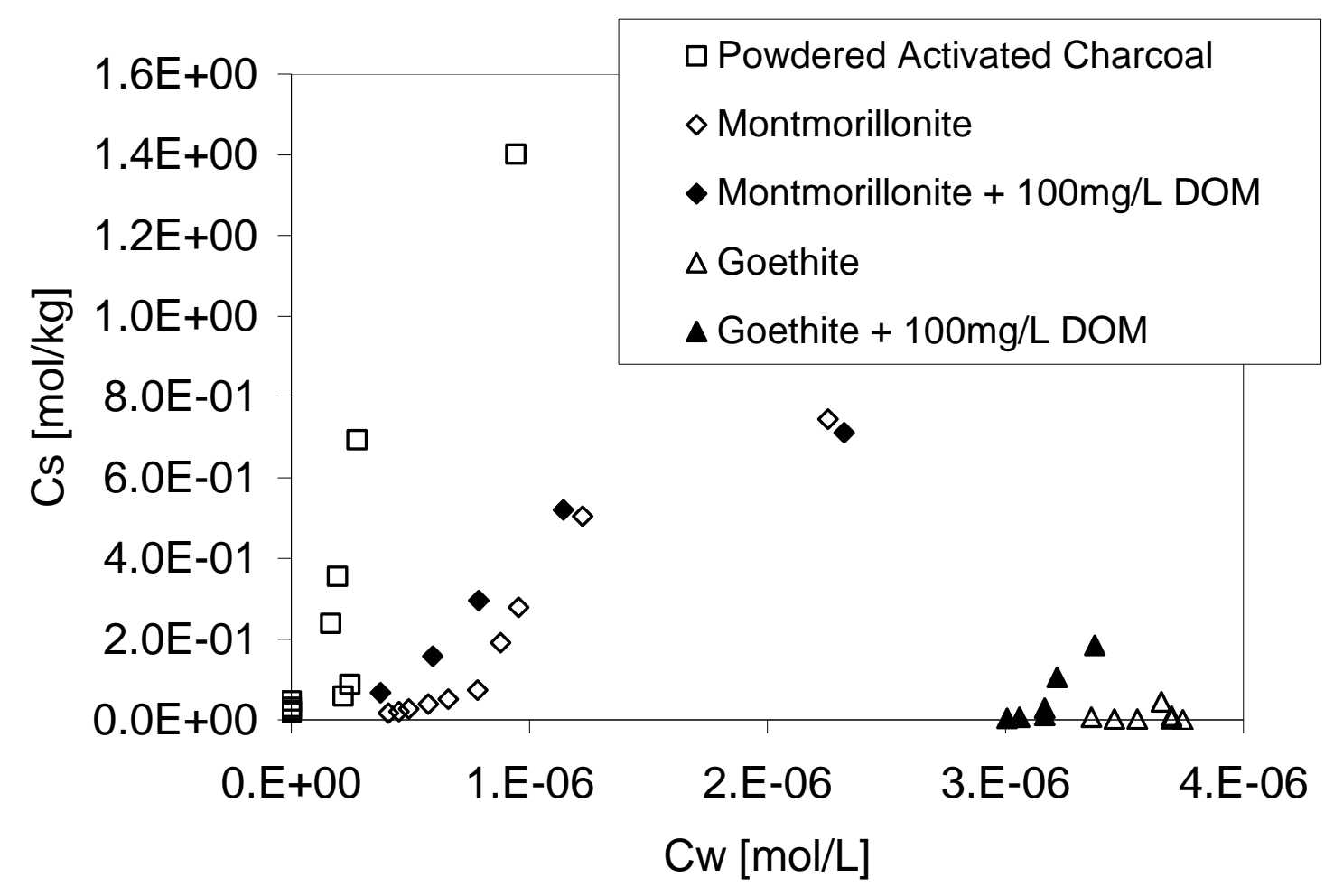


Figure 4

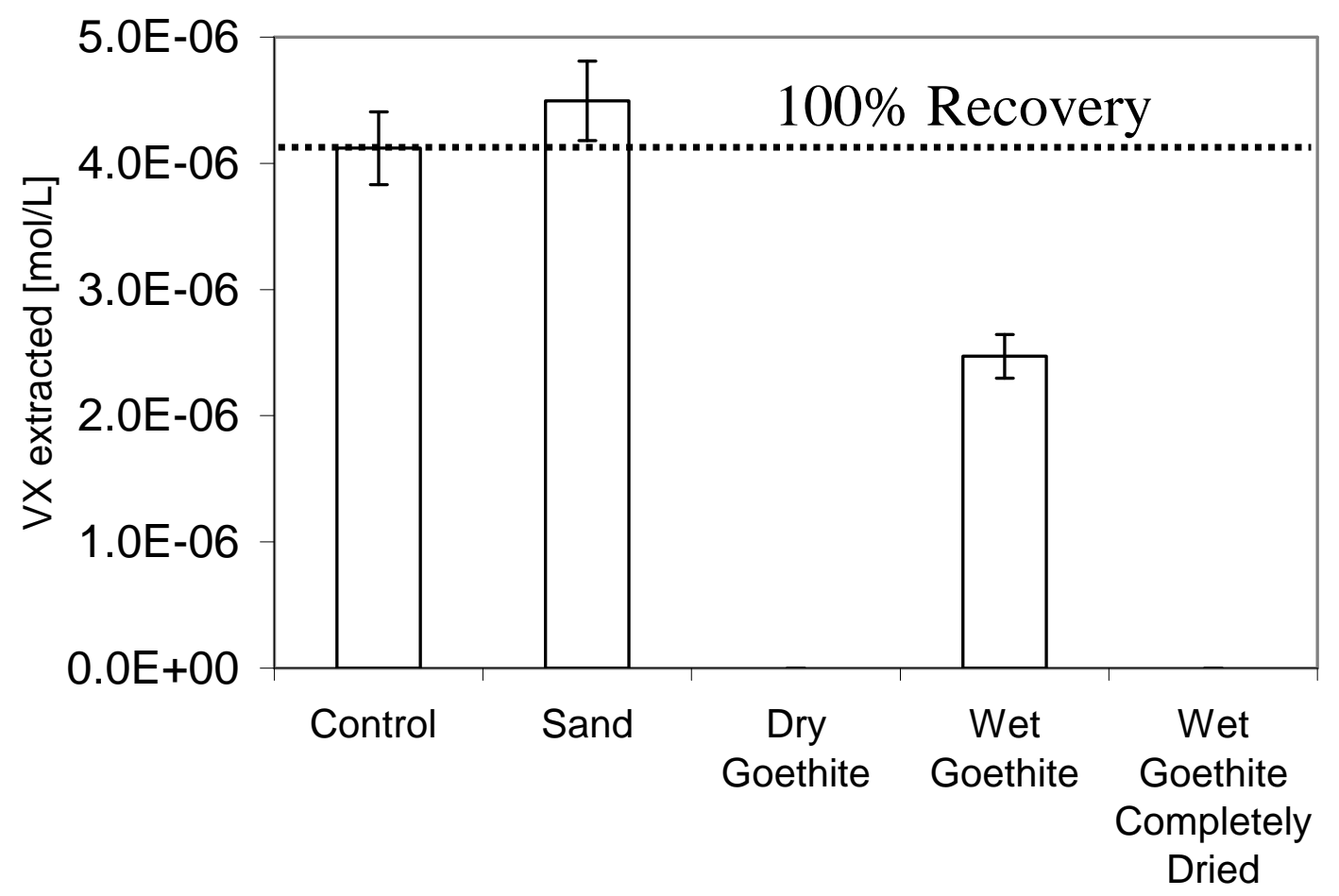

